Sport Training

\title{
Prevalence of burnout syndrome and perception by playing position in professional football players
}

\author{
Rodrigo Weyll Ferreira $^{1}$ (D), Victor Silveira Coswig ${ }^{1}$ (D), \\ Pedro Antonio Marques da Silva Monteiro ${ }^{2}$ (D), Jhonatan Welington Pereira Gaia ${ }^{1}$ (D), \\ Eduardo Macedo Penna ${ }^{1}$ (D), Daniel Alvarez Pires ${ }^{1}$ \\ ${ }^{1}$ Universidade Federal do Pará, Programa de Pós-Graduação em Ciências do Movimento \\ Humano, Castanhal, PA, Brasil; ${ }^{2}$ Faculdade de Desporto da Universidade do Porto, Porto, \\ Portugal.
}

\begin{abstract}
Associate Editor: Gustavo R Mota, Departamento de Ciências do Esporte, Universidade Federal do Triângulo Mineiro, Uberaba, MG, Brasil.
\end{abstract}

\begin{abstract}
Aim: The present study aimed to investigate the indicators of burnout, to determine whether playing position affects the perception of syndrome dimensions, and to identify burnout prevalence in professional football players. Methods: The participants were 100 professional football players (mean age $24.3 \pm 4.6$ years and meantime as a professional athlete of $9.2 \pm 4.5$ years) who were divided into three groups: 27 forwards, 34 midfielders, and 39 defenders. The Athlete Burnout Questionnaire (ABQ) and a sociodemographic questionnaire were applied. Results: The results show that a) the majority of athletes had low burnout indicators, b) there was no difference in the perception of burnout dimensions by playing position, and c) the prevalence of athletes with burnout, whether mild, moderate, or severe, was 13\%. Conclusion: The variable of playing position was not a determinant of perception of burnout dimensions among the forwards, midfielders, and defenders. Nonetheless, the prevalence of burnout deserves attention, as the negative effects of this syndrome may exert impacts on health, well-being, and sports performance, making athletes more likely to abandon their sport.
\end{abstract}

Keywords Burnout, Athletes, Football.

\section{Introduction}

Burnout syndrome is a response to the perception of chronic stress ${ }^{1}$. Concerns with its potential negative impacts on the performance and well-being of sports professionals have generated a series of studies on this topic ${ }^{2,3}$. One of the main characteristics of this syndrome is physical and emotional withdrawal, due to stress or dissatisfaction, from an activity previously perceived as enjoyable ${ }^{4,5}$. In sports, burnout is defined as a multidimensional syndrome characterized by i) physical and emotional exhaustion related to the high demands of training and competition, without a proper period for psychophysiological recovery; ii) a reduced sense of accomplishment, indicating dissatisfaction with one's skills and accomplishments in sports; and iii) sport devaluation, representing a lack of interest and concern about a sports career ${ }^{2,4}$.

Several models have been used to explain the development of burnout in athletes. However, the affectivecognitive model $^{6}$ is the most widely accepted ${ }^{7,8}$ and was adopted in the present study. This model comprises a four- stage process that is influenced by personality and motivation factors. The first stage consists of demands inherent to the sporting context to which the athlete is exposed (for example, high training loads). The second stage constitutes the athlete's cognitive appraisal of the situation (for example, being able to interpret a given situation as a threat). This appraisal leads to the third stage, the physiological response (for example, arousal). Finally, the fourth stage consists of the behavioural responses (for example, decreased performance) ${ }^{5,6}$. The evaluation process is continuous in this model, with burnout developing when the resources to cope with demands are inadequate . $^{6}$

Elite athletes are particularly susceptible to manifestations of burnout ${ }^{9}$. Such burnout occurs due to the high expectations, constant pressure for high performance, and demand for positive results in competitions placed on elite athletes ${ }^{10}$. High-performance sports are associated with high competition and training loads, which place athletes under pressure from physical, social, and psychological stressors ${ }^{11}$. Thus, athletes are susceptible to burnout when there is an imbalance between the stressors related to their 
participation in a sport and the resources used to cope with those stressors ${ }^{12}$. Moreover, because football is a popular sport in Brazil, with a daily presence in media coverage $\mathrm{e}^{13,14}$, there is a permanent demand by fans and managers for victories and titles ${ }^{15}$.

Given this context, several studies have been conducted to analyse burnout in Brazilian football ${ }^{13,15,16}$. Some findings in this context have identified that coping strategies are developed as an athlete's experience increases since the athlete is exposed to different sources of stress throughout his career; athletes are thus capable of developing problem-focused strategies that can mitigate or prevent high-burnout indicators ${ }^{17}$. Another study found that the variables of amotivation and overtraining can predict burnout in professional football players ${ }^{18}$. Moreover, few studies have provided the prevalence of burnout in soccer players ${ }^{19,20}$. Despite this gap, it has been suggested that there is an increase in the prevalence of burnout among athletes due to the increase in training loads ${ }^{20}$. Providing estimates on the prevalence of burnout in football players can increase the information base for coaches, athletes, and professionals involved in the football context and enable the development and implementation of strategies to prevent burnout ${ }^{21}$.

Football has different technical and tactical characteristics that are determined by playing position. For example, defenders position themselves based on the ball, the opponent, and teammates, with the intention of disrupting the opponent's ball possession ${ }^{22}$. For midfielders, mixed tactical behaviour is expected because they transition from defense to attack and attack to defense, while forwards have offensive characteristics, in contrast to the role of defenders ${ }^{23}$. Considering that different playing positions have different psychological characteristics, they may therefore have different susceptibility to the perception of burnout dimensions ${ }^{24}$. However, the relationship between playing position and burnout dimensions has not been investigated in Brazilian professional football players.

Given this gap, studies on burnout in professional football have practical implications because they can serve as references for the development of proposals for preventing and coping with the syndrome $\mathrm{e}^{25,26}$ that consider the actions performed during play by each group of athletes. In addition, the present study aims to investigate the indicators of burnout to assess whether the variable of playing position affects the perception of burnout dimensions and to identify burnout prevalence in professional football players. First, we hypothesized that athletes would have low indicators of burnout dimensions as evidenced in previous studies of football players ${ }^{15,17}$. Second, we expected to find a difference in the perception of burnout dimensions according to the variable of playing position.

\section{Methods}

\section{Participants}

The study included 100 professional football players, all males, who played for six first-division clubs from the football league of the Brazilian state of Pará (Campeonato Paraense) during the 2018 season and one club during the 2019 season. The participants had a mean age of $24.3 \pm 4.6$ years and an average of $9.2 \pm 4.5$ years of experience as a professional athlete. All athletes were in the competition phase. The athletes were divided into three groups based on playing position: a) 27 forwards (winger and center-forward), with a mean age of $23.4 \pm$ 3.6 years and a mean length of experience as professional athletes of $8.9 \pm 3.9$ years; b) 34 midfielders (central midfielders, playmakers and attacking midfielders), with a mean age of $23.7 \pm 4.9$ years and a mean length of experience as professional athletes of $8.2 \pm 4.4$ years; and c) 39 defenders (center-backs, fullbacks, and goalkeepers), with a mean age of $25.3 \pm 5.2$ years and a mean length of experience as professional athletes of $10.4 \pm 5.2$ years. Only athletes who had at least one year of experience as professional athletes, based on their first registration as a member of the federation (a requirement for becoming a professional player), were selected to participate in the study.

\section{Instruments}

The instrument used to measure burnout was the Athlete Burnout Questionnaire $(\mathrm{ABQ})^{4}$, validated for the Portuguese version, called the Questionário de Burnout para Atletas $(\mathrm{QBA})^{27}$. The QBA consists of 15 items: five items for the dimension of physical and emotional exhaustion (e.g., 'I feel "wiped out" from sport'), five items for the dimension of reduced sense of accomplishment (for example, 'I am not achieving much in sport'), and five items for the dimension of sport devaluation (for example, 'I don't care as much about the sport as I used to'). Responses are provided using a Likert scale with five frequencies of feelings: (1) almost never, (2) rarely, (3) sometimes, (4) frequently, and (5) almost always. The QBA has acceptable internal consistency (Cronbach's alpha $=0.82)$ and constructs validity ${ }^{28}$. Therefore, it has been frequently used in Brazilian sports settings ${ }^{17,29,30}$. In the present study, Cronbach's alpha coefficient was 0.77. In addition to the QBA, a sociodemographic questionnaire was used to collect data such as age, playing position, and length of experience as a professional athlete.

\section{Procedures and data collection}

Prior contact was made with each club's technical staff to clarify the procedures and objectives of the study. Next, the data were collected from the athletes in hotel rooms or at training centres. The researcher explained to 
the participants the objectives of the study and how to complete the instruments. Subsequently, the participants signed an informed consent form and completed the sociodemographic and QBA questionnaires. All athletes were in a competitive phase at the time of data collection. This study was approved by the Human Research Ethics Committee under opinion number 65796316.3.0000.0017.

\section{Statistical analysis}

The following classification was adopted for burnout indicators: participants who scored $\geq 3$ in one dimension were considered to have mild burnout, those who scored $\geq 3$ in two dimensions were considered to have moderate burnout, and those who scored $\geq 3$ in three dimensions were considered to have severe burnout ${ }^{31}$.

The normality of the data distribution was assessed with the Kolmogorov-Smirnov test. As the data presented a nonparametric distribution, median (Md) and quartiles (Q1; Q3) were used to characterize the results. The Kruskal-Wallis test with Dunn's post hoc test was used to assess possible differences in the perception of the burnout dimensions among the forward, midfielder, and defender groups. The effect size was calculated using the Eta squared $\left(\eta^{2}\right)$, with values from 0.000 to 0.003 indicating no effect, from 0.010 to 0.039 indicating a small effect, from 0.060 to 0.110 indicating an intermediate effect, and from 0.140 to 0.200 indicating a large effect ${ }^{32}$. The effect size and a $95 \%$ confidence interval were calculated to represent the analyses ${ }^{33}$. Statistical analyses were performed using the statistical package Prism, version 7 (GraphPad Software Inc., San Diego, CA, USA). The level of significance adopted was $p<0.05$.

\section{Results}

Table 1 presents the descriptive data for the scores on burnout dimensions for all athletes. The results indicate that the frequency of feelings of burnout ranged between almost never and rarely for the different dimensions, showing that the athletes had a low propensity for experiencing burnout.

Table 2 indicates whether perceptions of the dimensions of burnout were affected by playing position. The results show that the playing positions did not affect the perception of the dimensions of physical and emotional exhaustion, reduced sense of accomplishment, and sport devaluation.

Table 3 shows the prevalence of athletes affected by mild burnout ( $\geq 3$ in one dimension), moderate burnout ( $\geq 3$ in two dimensions), and severe burnout ( $\geq 3$ in three dimensions). The results identify that the prevalence of burnout was low. Of the total of athletes considered to be experiencing burnout, the highest percentage was observed in the occurrence of mild burnout, followed by moderate burnout, and, lastly, severe burnout.

Table 1 - Descriptive data on the burnout dimensions of the total number of athletes $(n=100)$.

\begin{tabular}{lccc}
\hline & PEE & RSA & DEV \\
\hline Min & 1.0 & 1.0 & 1.0 \\
Q1 & 1.4 & 1.6 & 1.2 \\
Md & 1.8 & 1.8 & 1.8 \\
Q3 & 2.2 & 2.4 & 2.2 \\
Max & 5.0 & 3.4 & 5.0 \\
\hline
\end{tabular}

Note. Min = Minimum value; Q1 $=25 \%$ Percentile; Md $=$ Median; Q3 = Percentile 75\%; Max $=$ Maximum value; $\mathrm{PEE}=$ Physical and Emotional Exhaustion; RSA = Reduced Sense of Accomplishment; $\mathrm{DEV}=$ Sport Devaluation

Table 2 - The perception of burnout dimensions by playing positions.

\begin{tabular}{|c|c|c|c|c|c|}
\hline \multirow[t]{3}{*}{ Dimension } & Md (Q1 - Q3) & Md (Q1 - Q3) & Kruskal-Wallis & $\eta^{2}$ & $95 \%$ CI \\
\hline & \multicolumn{2}{|c|}{ Playing position } & & & \\
\hline & Forwards $(n=27)$ & Midfielders $(n=34)$ & & & \\
\hline PEE & $1.8(1.4-2.6)$ & $1.8(1.4-2.2)$ & & 0.003 & -0.631 to 0.381 \\
\hline RSA & $1.8(1.6-2.2)$ & $1.9(1.8-2.5)$ & $\mathrm{p}=0.30$ & 0.002 & -0.405 to 0.606 \\
\hline \multirow[t]{2}{*}{ DEV } & $1.8(1.4-2.0)$ & $1.8(1.4-2.6)$ & & 0.000 & -0.461 to 0.549 \\
\hline & Forwards $(n=27)$ & Defenders $(n=39)$ & & & \\
\hline PEE & $1.8(1.4-2.6)$ & $1.6(1.2-2.0)$ & & 0.014 & -0.737 to 0.248 \\
\hline RSA & $1.8(1.6-2.2)$ & $1.8(1.6-2.2)$ & $\mathrm{p}=0.30$ & 0.002 & -0.589 to 0.393 \\
\hline \multirow[t]{2}{*}{ DEV } & $1.8(1.4-2.0)$ & $1.6(1.2-2.2)$ & & 0.026 & -0.824 to 0.164 \\
\hline & Midfielders $(n=34)$ & Defenders $(n=39)$ & & & \\
\hline PEE & $1.8(1.4-2.2)$ & $1.6(1.2-2.0)$ & & 0.004 & -0.596 to 0.325 \\
\hline RSA & $1.9(1.8-2.5)$ & $1.8(1.6-2.2)$ & $\mathrm{p}=0.30$ & 0.010 & -0.669 to 0.253 \\
\hline DEV & $1.8(1.4-2.6)$ & $1.6(1.2-2.2)$ & & 0.036 & -0.852 to 0.077 \\
\hline
\end{tabular}

Note. PEE $=$ Physical and Emotional Exhaustion; RSA = Reduced Sense of Accomplishment; DEV = Sport Devaluation; Md = Median; Q1 = 25\% Percentile; Q3 = Percentile 75\%; $\eta 2=$ effect size; $\mathrm{CI}=$ confidence interval. 
Table 3 - Prevalence of athletes affected by mild, moderate, and severe burnout.

\begin{tabular}{lcccc}
\hline & Mild & Moderate & Severe & Total \\
\hline Athletes not affected & - & - & - & $\mathbf{8 7}(\mathbf{8 7 \%})$ \\
Athletes affected & $\mathbf{1 0}(\mathbf{1 0 \% )}$ & $\mathbf{2 ( 2 \% )}$ & $\mathbf{1}(\mathbf{1 \% )}$ & $\mathbf{1 3 ( 1 3 \% )}$ \\
Forwards & $2(2 \%)$ & $0(0 \%)$ & $1(1 \%)$ & $3(3 \%)$ \\
Midfielders & $5(5 \%)$ & $1(1 \%)$ & $0(0 \%)$ & $6(6 \%)$ \\
Defenders & $3(3 \%)$ & $1(1 \%)$ & $0(0 \%)$ & $4(4 \%)$ \\
Total of athletes & & & & $\mathbf{1 0 0}(\mathbf{1 0 0 \% )}$ \\
\hline
\end{tabular}

Note. Numbers in bold refer to the total number of athletes; Numbers without bold refer to the group of athletes affected by burnout.

\section{Discussion}

The aims of this study were to 1) investigate the indicators of burnout, 2) determine whether playing position affects the perception of burnout dimensions, and 3) identify burnout prevalence in professional football players. Two hypotheses were tested in this study. First, we hypothesized that athletes would have low indicators of burnout dimensions. Second, we expected to find different perceptions of burnout dimensions according to the playing position. In summary, the main results show that a) the majority of athletes had low burnout indicators; b) there was no difference in the perception of burnout dimensions among the defenders, midfielders, and forwards; and c) the total prevalence of athletes affected by burnout, whether mild, moderate, or severe, was $13 \%$.

Considering the indicators of burnout dimensions, the reduced value for physical and emotional exhaustion suggests that, in general, these athletes made adequate psychophysiological adjustments to the demands of training and competition ${ }^{13,15}$. In addition to psychophysiological adaptation, one study has suggested that low indicators for the physical and emotional exhaustion dimension are reported by athletes with low levels of subjective stress outside the sport and with adequate coping with stressors ${ }^{10}$. This finding corroborates the affective-cognitive model, which suggests that effective coping strategies can mitigate burnout physically and emotionally ${ }^{6}$. Another possible explanation is that athletes may present a high level of intrinsic motivation because intrinsically motivated athletes have a reduced perception of psychophysiological burnout ${ }^{6,34}$.

Similar to the physical and emotional exhaustion, the reduced sense of accomplishment dimension had low indicators, which shows that the athletes were satisfied with their professional skills and achievements ${ }^{2,15}$. A meta-analysis showed that social support from people considered important in the sport setting, such as coaches and teammates, may be relevant for athletes' professional accomplishments by providing instructions that help improve their skills, which helps maintain the required performance in high-performance sports ${ }^{35}$. Therefore, social support can reduce burnout in athletes, in addition to helping with performance ${ }^{6}$. In addition, athletes who have low indicators for this dimension still feel the desire to participate in the sport, feel intrinsically motivated, and are aware that their participation in the sport promotes personal growth ${ }^{9}$.

A study showed that high indicators of the sport devaluation dimension are experienced by athletes with little disposition to make psychosocial sacrifices, who are not willing to tolerate the extensive psychosocial stresses inherent to elite sport and therefore debate whether their commitment to the sport is worthwhile ${ }^{10}$. In addition, negative interactions, such as rejection by coaches and teammates, may indicate that an athlete's contribution is not important ${ }^{35}$. However, our findings suggest the opposite because the reduced frequency of the dimension of feelings of sport devaluation suggests that the athletes in this study remain interested in, committed to, and motivated by their sport ${ }^{8,15}$. The results also suggest that athletes may be willing to make psychosocial sacrifices, are in a supportive environment even when injured, and experience low levels of stress in the sport setting ${ }^{10}$. Consequently, the first hypothesis about low burnout indicators was confirmed for the three dimensions.

The intergroup comparison of the perception of burnout dimensions by playing position did not indicate differences among forwards, midfielders, and defenders. Thus, this result does not confirm the second hypothesis. Although playing positions differ in their psychological characteristics $^{24}$, no difference has previously been found in the perception of burnout by playing position ${ }^{25}$, which accords with our results. One possible explanation for this finding is that football is a collective sport. Thus, the perception of burnout may be decreased ${ }^{36}$ due to the sharing of stressful demands with teammates, which can increase intrinsic motivation and decrease the perception of sport devaluation, thereby allowing athletes to deal emotionally with exhaustion and poor performance ${ }^{35}$.

Regarding the prevalence of burnout, our results are in accordance with the literature, which reports the prevalence of high indicators of burnout among the athlete population ranging from $1 \%$ to $2 \%{ }^{20}$. In addition to the prevalence of high-burnout indicators, the total prevalence of athletes with a burnout in this study is in line with the estimate that $10 \%$ of athletes experience some level of burnout during their sports career ${ }^{37}$. Although the prevalence of burnout was relatively low, at $13 \%$, it is nonetheless an indicator that requires attention because burnout factors are associated with mental health in athletes. In fact, some athletes may present high levels of stress throughout their careers, causing psychobiological disorder $^{38,39}$. Moreover, lower levels of coping strategies may lead to the perception of certain situations in the sport setting as threatening and stressful ${ }^{12,17}$, and low levels of intrinsic motivation may also put athletes at risk of experi- 
encing higher levels of burnout ${ }^{36}$. Therefore, the negative adaptations associated with stress, inefficient coping strategies, and lack of motivation place athletes at risk of developing burnout and consequently may ultimately contribute to the prevalence of burnout ${ }^{18}$.

The present study indicates, as a practical application, that the monitoring of burnout does not need to be conducted in a specific way by playing position. Nevertheless, this assertion does not rule out the need to monitor burnout indicators in athletes in general.

Despite the contributions provided for a better understanding of the perception of burnout in professional football players, two limitations of the study are worth noting. The first is the cross-sectional nature of the study, which does not allow for the identification of possible changes in burnout indicators that may occur during the competition phase. The second is related to the healthy worker effect because the data collection performed only with currently active athletes does not acknowledge the possible athletes affected by burnout who have dropped out of their athletic career, given that retirement from the sport is one of the consequences of the syndrome.

For future research, we suggest the adoption of longitudinal designs to investigate burnout syndrome to develop a better understanding of the cause-and-effect relationship between playing position and other psychological variables in professional football players, as well as to monitor changes in the perception of burnout by playing position during the preseason, competitive phase, and postseason. In addition, future research should seek to develop a specific reference table for professional football, as was created in a study for soccer athletes of the under20 category ${ }^{40}$. Finally, future studies should address players aged 30 and older, since the profile of this group for burnout may be different.

\section{Conclusion}

Professional football players, in general, experience reduced frequencies of feelings of burnout in its different dimensions. Despite representing different technical and tactical conditions, playing position was not a determinant in the perception of burnout dimensions among forwards, midfielders, and defenders. Lastly, the finding that burnout occurs in approximately one in eight athletes deserves attention because the negative effects of the syndrome may exert impacts on health, well-being, and sports performance, making these athletes more likely to stop playing the sport.

\section{Declaration of Conflicting Interests}

The author(s) declared no potential conflicts of interest with respect to the research, authorship, and/or publication of this article.

\section{Acknowledgments}

This study was financed in part by the Coordenação de Aperfeiçoamento de Pessoal de Nível Superior - Brasil (CAPES) - Finance Code 001. The authors also thank PROPESP-UFPA for support funding English revision.

\section{References}

1. Chyi T, Lu FJH, Wang ETW, Hsu YW, Chang KH. Prediction of life stress on athletes' burnout: The dual role of perceived stress. PeerJ. 2018;(1):1-14.

2. Gustafsson H, Defreese JD, Madigan DJ. Athlete burnout: review and recommendations. Curr Opin Psychol. 2017;16:109-13.

3. Madigan DJ, Rumbold JL, Gerber M, Nicholls AR. Coping tendencies and changes in athlete burnout over time. Psychol Sport Exerc. 2020;48.

4. Raedeke, T. D. Smith AL. Development and Preliminary Validation of an Athlete Burnout Measure. J Sport Exerc Psychol. 2001;23:281-306.

5. Gustafsson H, Kentta G, Hassmén P. Athlete burnout: an integrated model and future research directions. Int Rev Sport Exerc Psychol. 2011;4(1):3-24.

6. Smith RE. Toward a Cognitive-Affective Model of Athletic Burnout. J Sport Psychol. 1986;8:36-50.

7. Smith EP, Hill AP, Hall HK. Perfectionism, Burnout and Depressive Symptoms in Youth Soccer Players: A Longitudinal Study. J Clin Sport Psychol. 2018;12(2):179-200.

8. Goodger K, Gorely T, Lavallee D, Harwood C. Burnout in sport: A systematic review. Sport Psychol. 2007;21:127-51.

9. Bicalho CCF., Costa VT. Burnout in Elite Athletes : A Systematic Review. Cuad Psicol del Deport. 2018;18(1):89102.

10. Granz HL, Schnell A, Mayer J, Thiel A. Risk profiles for athlete burnout in adolescent elite athletes: A classification analysis. Psychol Sport Exerc. 2019;41:130-41.

11. Madigan DJ, Hill AP, Anstiss PA, Mallinson-Howard SH, Kumar S. Perfectionism and training distress in junior athletes: The mediating role of coping tendencies. Eur J Sport Sci. 2018;18(5):713-21.

12. Pacewicz CE, Gotwals JK, Blanton JE. Perfectionism, coping, and burnout among intercollegiate varsity athletes: A person-oriented investigation of group differences and mediation. Psychol Sport Exerc. 2018;35:207-17.

13. Giacomoni, C. Fonseca GMM. Principais Indicadores de Burnout em Jovens Atletas de Futebol. Rev Mackenzie Educ Física e Esporte. 2014;13(2):106-23.

14. Oliveira AB, Penna EM, Pires DA. Síndrome de Burnout em Árbitros de Futebol. Rev Psicol del Deport. 2017;27 (1):31-6.

15. Bemfica TEB, Fagundes LHS, Pires DA, Costa V.T. Efeito da temporada sobre a percepção da síndrome de burnout por atletas de futebol profissional. Rev Bras Ciência e Mov. 2013;21(4):142-50.

16. Verardi CEL, Santos AB, Nagamine KK, Carvalho T de, Miyazaki MC de OS. Burnout e enfrentamento em jogadores de futebol: fases pré e durante competição. Rev Bras Med do Esporte Esporte. 2014;20(4):272-5. 
17. Pires DA, Ferreira RW, Vasconcelos ASB, Penna EM. Dimensões de Burnout, Estratégias de Coping e Tempo de Prática como Atleta Federado em Jogadores Profissionais de Futebol. Cuad Psicol del Deport. 2019;19(2):167-77.

18. Fagundes LHS, Noce F, Albuquerque MR, de Andrade AGP, Teoldo da Costa V. Can motivation and overtraining predict burnout in professional soccer athletes in different periods of the season? Int J Sport Exerc Psychol. 2019;1-16.

19. Francisco D, Fayos GDL, Arce C. Burnout en deportistas : Prevalencia del síndrome a través de dos medidas Burnout in athletes: Prevalence of the syndrome through two measures Burnout em atletas : Prevalência da síndrome através de duas medidas. Cuad Psicol del Deport. 2014;14(1):29-38.

20. Gustafsson H, Kenttä G, Hassmén P, Lundqvist C. Prevalence of burnout in competitive adolescent athletes. Sport Psychol. 2007;21(1):21-37.

21. Nixdorf I, Beckmann J, Nixdorf R, Nicholls AR. Psychological Predictors for Depression and Burnout Among German Junior Elite Athletes. Front Psychol. 2020;11:1-13.

22. Guimarães M, Caldas G, Lima R, Paoli P. As posições no futebol e suas especificidades. Rev Bras Futeb. 2014;7 (2):71-83.

23. Gonçalves E, Rezende ALG de, Teoldo I. Comparação entre a performance tática defensiva e ofensiva de jogadores de futebol Sub-17 de diferentes posições. Rev Bras Ciencias do Esporte. 2017;39(2):108-14

24. Junge A, Dvorak J, Rösch D, Graf-Baumann T, Chomiak J, Peterson L. Psychological and sport-specific characteristics of football players. Am J Sports Med. 2000;28(5):22-8.

25. Verardi CEL, Nagamine KK, Neiva CM, Filho DMP, Domingos NAM, Ciolac EG, et al. Burnout and playing position : a study of Brazilian soccer players. J Phys Educ Sport. 2014;14(3):324-30.

26. Monfared SS, Lebeau JC, Mason J, Cho SK, Basevitch I, Perry I, et al. A Bio-Physio-Psychological Investigation of Athletes' Burnout. Res Q Exerc Sport. 2020;1-10.

27. Pires, DA, Brandão MRF, Silva $\mathrm{CB}$. Validação do questionário de burnout para atletas. Rev da Educ Física/UEM. 2006;17(1):27-36.

28. Souza AC, Edinêis NMCA, Guirardello E de B. Psychometric properties in instruments evaluation of reliability and validity. Epidemiol e Serviços Saúde. 2017;26(3):649-59.

29. Pires DA, Bara Filho MG, Debien PB, Coimbra DR, Ugrinowitsch H. Burnout e coping em atletas de voleibol: Uma análise longitudinal. Rev Bras Med do Esporte. 2016;22 (4):277-81.

30. Fortes, LS, Costa, BDV, Ferreira MEC. A restrição alimentar e os sintomas de bulimia estão relacionados aos sentimentos de burnout em atletas de esportes coletivos? Rev Bras Ciencias do Esporte. 2018;26(2):12-7.
31. Lamont-Mills A, Peter C, Steven A. Re-evaluating athlete burnout in pre-elite, adolescent athletes: An Australian experience. 2017. p. 1-5.

32. Cohen J. Statistical Power Analysis for the Behavioral Sciences. 2nd ed. Statistical Power Analysis for the Behavioral Sciences. 1988.

33. Lenhard W, Lenhard A. Calculation of Effect Sizes. Retrieved from: https://www.psychometrica.de/effect_size. html. Dettelbach (Germany): Psychometrica. 2016;

34. Madigan DJ, Stoeber J, Passfield L. Motivation mediates the perfectionism-burnout relationship: A three-wave longitudinal study with junior athletes. J Sport Exerc Psychol. 2016;38(4):341-54.

35. Pacewicz CE, Mellano KT, Smith AL. A meta-analytic review of the relationship between social constructs and athlete burnout. Psychol Sport Exerc. 2019;43:155-64.

36. Peraita-Costa I, Llopis-Morales A, Marí-Bauset S, MaríSanchis A, Marí-Sanchis S, Morales-Suárez-varela M. Burnout syndrome risk in child and adolescent tennis players and the role of adherence to the mediterranean diet. Int $\mathrm{J}$ Environ Res Public Health. 2020;17(3).

37. Madigan DJ, Gustafsson H, Smith A, Raedeke T, Hill AP. The BASES Expert Statement on Burnout in Sport. J Sports Sci. 2019;(61):6-7.

38. Isoard-Gautheur S, Guillet-Descas E, Gustafsson H. Athlete burnout and the risk of dropout among young elite handball players. Sport Psychol. 2016;30(2):123-30.

39. Moen F, Hrozanova M, Stiles TC, Stenseng F. Burnout and Perceived Performance Among Junior Athletes-Associations with Affective and Cognitive Components of Stress. Sports. 2019;7(7):171.

40. Bicalho CCF, Costa IT da, Noce F, Costa VT da. Prevalence of Burnout in Soccer Athletes of the Under-20 Category Over a Sports Season. J Phys Educ. 2020;31(1).

\section{Corresponding author}

Rodrigo Weyll Ferreira. Conj. Império Amazônico, Bl:08, Ent: B, Ap:013, Cep:66613-080, Belém, PA, Brazil. E-mail: rodrigo.weyll.ferreira@castanhal.ufpa.br.

Manuscript received on January 21, 2021

Manuscript accepted on March 3, 2021

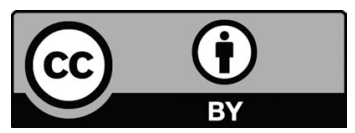

Motriz. The Journal of Physical Education. UNESP. Rio Claro, SP, Brazil - eISSN: 1980-6574 - under a license Creative Commons - Version 4.0 